\title{
Nanocomposite ZnO:MWCNT Thin Films for Li-Ion Batteries Prepared via Reactive Magnetron Sputtering
}

\author{
M.O. Guler*, T. Cetinkaya, O. Cenher, U. Tocoglu and H. Akbulut \\ Sakarya University, Engineering Faculty, Department of Metallurgical \& Materials Engineering \\ Esentepe Campus, 54187, Sakarya, Turkey
}

\begin{abstract}
In this study, $\mathrm{ZnO} / \mathrm{MWCNT}$ buckypaper nanocomposite structures were obtained as an anode electrode material for Li-ion batteries. MWCNT based buckypapers were produced via vacuum filtration techniques and the surfaces of the buckypapers were coated with $\mathrm{ZnO}$ in order to increase stability and mechanical integrity during charging and discharging processes. The effect of deposition powers on the battery performance is also investigated.
\end{abstract}

DOI: $10.12693 /$ APhysPolA.125.319

PACS: 82.47.Aa, 61.48.De, 77.55.hf

\section{Introduction}

Currently, lithium ion insertion materials have attracted great interests since they can be used as active electrode materials in rechargeable Li-ion batteries (LIBs) for potential applications such as portable electronics and hybrid electrical vehicles. $\mathrm{ZnO}$ has been considered as one of the most important anode electrode material in LIBs due to its high theoretical specific capacity $\left(978 \mathrm{mAh} \mathrm{g}^{-1}\right)$, compared to traditional graphite anode [1-4]. However, exponential volumetric expansion usually occurs during the lithiuation and delithiuation processes [5], which leads to pulverization of electrode and rapid capacity degradation. Therefore, its commercial application in LIBs anode has been significantly hindered.

Many metal oxide based anode electrodes having pulverization and degradation problems during lithiuation and delithiuation processes were widely studied. In order to prevent these obstacles and extend the cycling life of metal oxide based anode electrodes, metal oxide particles were integrated with carbon based matrices as an inactive buffer layer due to their intrinsic mechanical durability and good electronic properties [6-8]. In this study, we report a new type of nanostructure, $\mathrm{CNTs}-\mathrm{ZnO}$ nanocomposite structures, which integrate both electronic conductivity and buffering matrix design strategies. The CNTs- $\mathrm{ZnO}$ nanostructured electrodes have been prepared and applied as anode materials for lithium-ion batteries, which exhibit higher lithium storage capacities and better cycling performance compared to single $\mathrm{CNTs}$ and $\mathrm{ZnO}$ electrodes. Thin films of $\mathrm{ZnO}$ nanostructures were formed via rf magnetron sputtering.

\section{Experimental details}

The multiwalled carbon nanotubes (MWCNTs) of $50 \mathrm{~nm}$ in diameter and $1.00 \mu \mathrm{m}$ in length used in this research were provided by Arry International Co., Ltd.
(Germany), produced using a chemical vapor deposition (CVD) method. As received MWCNTs were heat treated at $350{ }^{\circ} \mathrm{C}$ for $8 \mathrm{~h}$ in order to remove the amorphous carbon. MWCNTs were then dispersed in nitric acid solution and further refluxed at $140^{\circ} \mathrm{C}$ with magnetic stirring for the removal of metal catalysts contaminants. Chemical oxidation of MWCNTs was carried out with a mixture of $\mathrm{H}_{2} \mathrm{SO}_{4}$ and $\mathrm{HNO}_{3}$ acids in ratio $3: 1$ for $3 \mathrm{~h}$. The functionalized MWCNTs were first dispersed into water by the aid of SDS surfactant and sonicated to form a well-dispersed suspension which subsequently was vacuum filtered through PVDF membrane filters of $220 \mathrm{~nm}$ pore size to form buckypapers. The produced buckypapers were then coated with $\mathrm{ZnO}$ via magnetron sputtering techniques. The base pressure was reduced to $1.0 \times 10^{-3} \mathrm{~Pa}$, then the targets were pre-sputtered for 5 min in order to eliminate the contaminant from target surfaces under $0.55 \mathrm{~Pa}$, followed by injected high purity $(99.999 \%)$ oxygen reactive gas into the vacuum chamber to form zinc oxide thin films. The argon and oxygen flow rate were fixed at constant value for all coatings and the effect of coating power on the electrochemical performance is investigated.

The structure of the deposited films was characterized by means of X-ray diffraction (XRD, Rigaku D/max 2200 system with thin film attachment). The morphology was observed by scanning electron microscopy (JSM-6060 LV system). Coin-type (CR2016) test cells were assembled in an argon-filled glove box, directly using the $\mathrm{ZnO}$ coated CNT buckypapers as the working electrode, a lithium metal foil as the counter electrode, a micro porous polypropylene (PP) membrane (Cellgard 2400) as the separator, and $1 \mathrm{M}$ solution of $\mathrm{LiPF}_{6}$ in ethylene carbonate (EC) and dimethyl carbonate (DMC) (1:1 by weight) as the electrolyte. The cells were cyclically tested on a MTI Model BST8-MA electrochemical analyzer using different current densities over a voltage range of $0.2-$ $2.5 \mathrm{~V}$.

* corresponding author 


\section{Results and discussions}

Figure 1 shows the SEM image of the produced buckypapers. As can be seen from the figures, a highly entangled CNT network, with numerous intersection points consists of long, curled and highly random oriented mesoporous structure. The self standing property of the produced paper-like structure is due to the Van der Waals forces and mechanical locking of the MWCNTs within the buckypaper. The SEM image of a cross-section of a representative sheet (Fig. 1b) indicates an almost homogeneous CNT deposition through the thickness giving rise to a dense morphology.
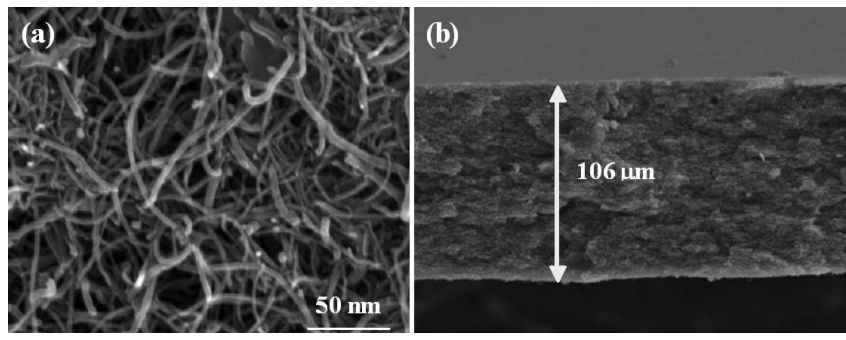

Fig. 1. SEM images of (a) surface and (b) cross-section area of the MWCNT based buckypapers.

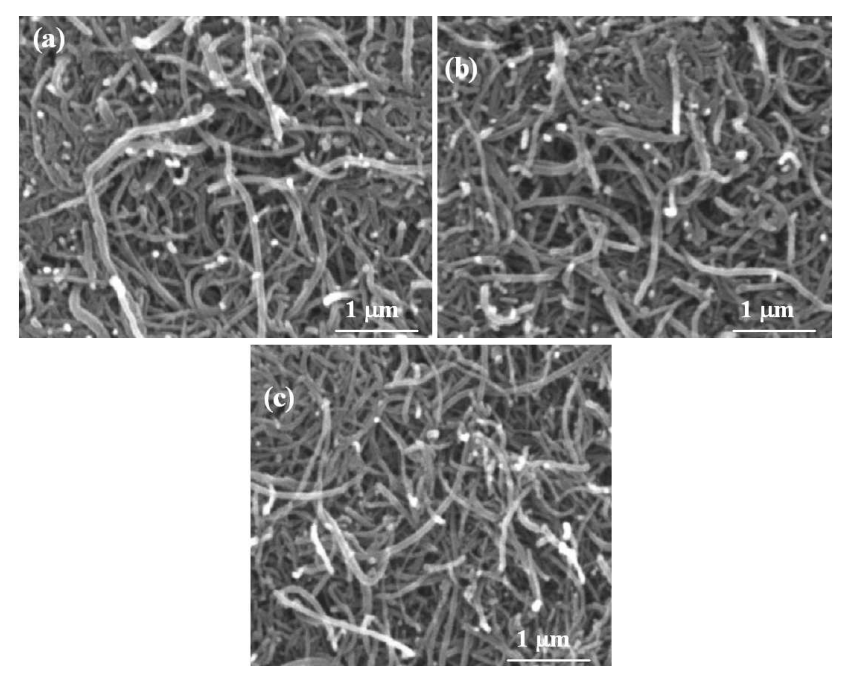

Fig. 2. SEM images of the films deposited by using (a) $75 \mathrm{~W}$, (b) $100 \mathrm{~W}$, and (c) $125 \mathrm{~W}$ rf powers under $10 \%$ oxygen gas pressures.

Figure 2 shows the surfaces of the buckypapers after reactive magnetron sputtering process. The SEM images revealed that the $\mathrm{ZnO}$ is considered to be selectively nucleated and uniformly deposited on the surface of CNTs by the reactive magnetron sputtering process. No obvious separated $\mathrm{ZnO}$ bulk particles are evident apart from those deposited on CNTs. The CNTs coated with ZnO are entangled and interconnected to form a uniform network with a three-dimensional and highly mesoporous structure.

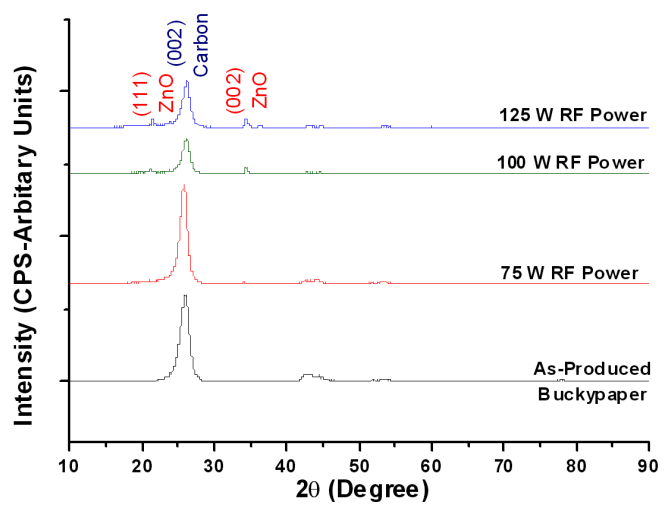

Fig. 3. XRD spectra of the as-produced buckypaper and thin films deposited by using varying RF powers.

Figure 3 shows the XRD patterns of the produced buckypaper and $\mathrm{ZnO}$ coated buckypaper by using varying rf powers. The XRD results indicate that the $\mathrm{ZnO}$ thin films were obtained on the surfaces of buckypapers. All peaks were assigned to carbon (JCPDS 026-1080) and hexagonal zinc oxide (JCPDS-36-1451). XRD paterns also exhibit the (002) and (111) peaks, which indicates that the films are highly oriented with their crystallographic $c$-axis perpendicular to the substrate, irrespective of sputtering power. However, intensities of the peaks were shown a variation with increasing $R F$ power. The diffraction intensity of the (002) peak maximized at sputtering power of $125 \mathrm{~W}$ which clearly indicates that the crystallinity of the films was improved with increasing RF power.
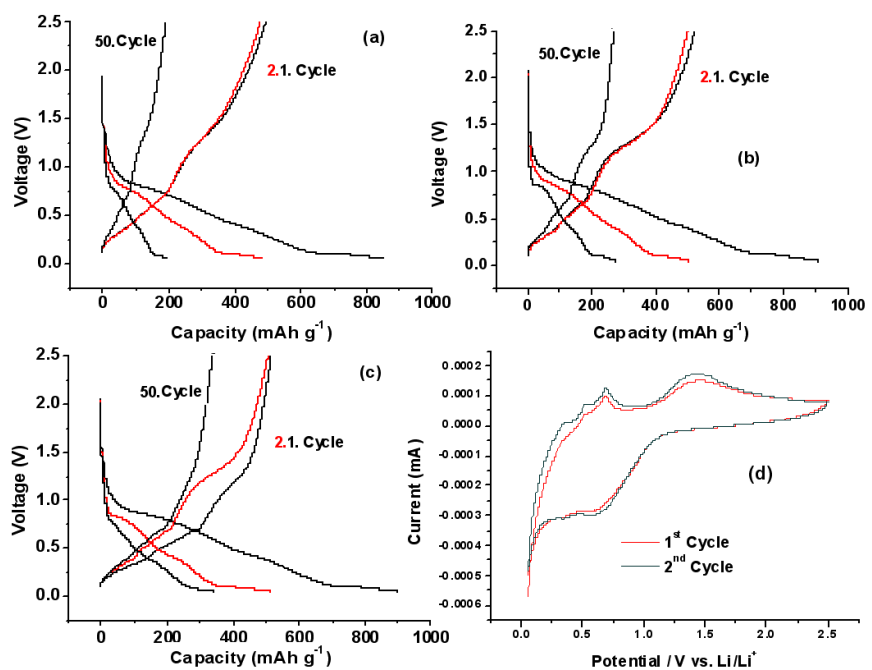

Fig. 4. Voltage-capacity curves of the deposited under (a) $125 \mathrm{~W}$, (b) $100 \mathrm{~W}$, (c) $75 \mathrm{~W}$ rf powers, and (d) cyclic voltammograms of $\mathrm{ZnO} / \mathrm{MWCNT}$ nanocomposite anode electrodes.

The galvanostatic discharge-charge curves at current density $14 \mathrm{~mA} \mathrm{dm}^{-2}(1 \mathrm{C})$ of MWCNT/ZnO anode elec- 
trode between 0.2 and $2.5 \mathrm{~V}$ vs. $\mathrm{Li}^{+} / \mathrm{Li}$ and cycling performances are presented in Fig. $4 \mathrm{a}-\mathrm{c}$. As can be deduced from the figures, best results were obtained after $50 \mathrm{cy}-$ cles with a capacity of $257 \mathrm{mAh} \mathrm{g}^{-1}$. Figure $4 \mathrm{~d}$ shows the cyclic voltammograms $(C V)$ of porous $\mathrm{ZnO}$ nanocomposite structures measured between 0 and $2.5 \mathrm{~V}$ at a scan rate of $0.5 \mathrm{mV} \mathrm{s}^{-1}$. As can be seen, two peaks were obtained between $0.35 \mathrm{~V}$ and $0.70 \mathrm{~V}$ which can be attributed to the reduction of $\mathrm{ZnO}$ into $\mathrm{Zn}$ and the formation of lithium-zinc alloy. However, four oxidation peaks were obtained in the subsequent anodic scan which can be assigned to the multi-step dealloying process of lithiumzinc alloy $\left(\mathrm{LiZn}, \mathrm{Li}_{2} \mathrm{Zn}_{3}, \mathrm{LiZn}_{2}\right.$ and $\left.\mathrm{Li}_{2} \mathrm{Zn}_{5}\right)$. In addition, a broad oxidation peak is found at $1.54 \mathrm{~V}$, which may relate to the decomposition of $\mathrm{Li}_{2} \mathrm{O}$. The integral area of the curves were seen to be equal which clearly indicates that $\mathrm{ZnO} / \mathrm{MWCNT}$ based anode electrodes are highly reversible and MWCNT buckypapers improved the Li electroactivity of the $\mathrm{ZnO}$ nanoparticles because of their beneficial effect on the conductivity, efficient electron paths, and aggregation control of active nanoparticles.

\section{Conclusions}

In this study, highly mesoporous MWCNT based buckypapers were produced via vacuum filtration techniques. The surfaces of the MWCNT based buckypapers were then coated with $\mathrm{ZnO}$ in order to increase the electrochemical performance of the buckypapers which could be used as an anode material in $\mathrm{Li}$ ion batteries. The results have shown that best results were obtained for the deposited under $75 \mathrm{~W}$ rf power which could be attributed to the finer nanograins as revealed by the XRD results. Obtaining nanograins over the surfaces of the buckypapers can increase the surface area structure and may alleviate the change of the cell volume during charge and discharge cycles. Furthermore, buckypaper shells in the composites optimize the electrochemical performances of $\mathrm{ZnO}$ electrode materials. Therefore, core-shell $\mathrm{ZnO} / \mathrm{MWCNT}$ composites are worth extensively exploiting as anode materials for lithium ion batteries.

\section{Acknowledgments}

This work is supported by the Scientific and Technological Research Council of Turkey (TÜBİTAK) under the contract number 109M464. The authors thank the TÜBİTAK MAG workers for their financial support.

\section{References}

[1] J.P. Liu, Y.Y. Li, R.M. Ding, J. Jiang, Y.Y. Hu, X.X. Ji, Q.B. Chi, Z.H. Zhu, X.T. Huang, J. Phys. Chem. C 113, 5336 (2009).

[2] J.P. Liu, Y.Y. Li, X.T. Huang, G.Y. Li, Z.K. Li, Adv. Funct. Mater. 18, 1448 (2008).

[3] C.Q. Zhang, J.P. Tu, Y.F. Yuan, X.H. Huang, X.T. Chen, F. Mao, J. Electrochem. Soc. 154, A65 (2007).

[4] K.T. Nam, D.W. Kim, P.J. Yoo, C.Y. Chiang, N. Meethong, P.T. Hammond, Y.M. Chiang, A.M. Belcher, Science 312, 885 (2006).

[5] D.W. Kim, I.S. Hwang, S.J. Kwon, H.Y. Kang, K.S. Park, Y.J. Choi, K.J. Choi, J.G. Park, Nano Lett. 7, 3041 (2007).

[6] L. Yuan, K. Konstantinov, G.X. Wang, H.K. Liu, S.X. Dou, J. Power Sources 146, 180 (2005).

[7] L.J. Fu, H. Liu, C. Li, Y.P. Wu, E. Rahm, R. Holze, H.Q. Wu, Solid State Sci. 8, 113 (2006).

[8] B. Ellis, P.S. Herle, Y.H. Rho, L.F. Nazar, R. Dunlap, L.K. Perry, D.H. Ryan, Faraday Discuss. 134, 119 (2007). 